\title{
Modelo conceitual de inteligência organizacional aplicada à função manutenção
}

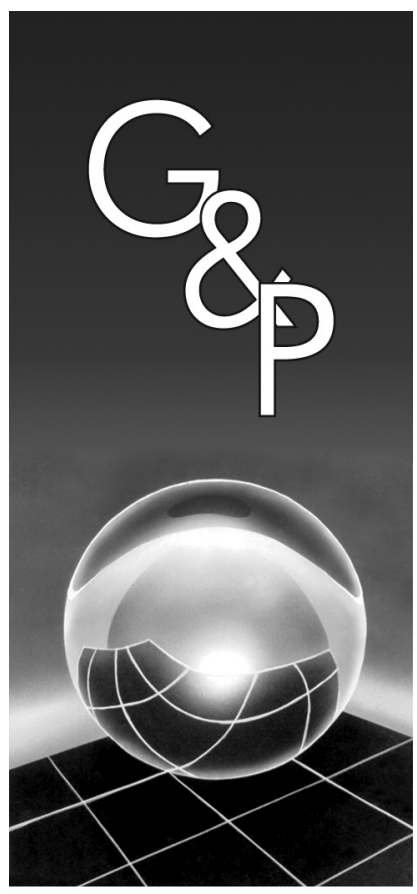

Robson de Paula Alves

Orandi Mina Falsarella

\section{Resumo}

Apresenta uma investigação, por meio de pesquisa bibliográfica, dos Sistemas de Informação, das ferramentas e dos métodos de Inteligência Organizacional, com vistas à sua aplicação em ambientes de Manutenção como instrumentos para potencializar a gestão dessa importante função dentro de processos produtivos. Para tanto, são abordados inicialmente os conceitos da Manutenção, assim como sua crescente relevância e destaque. Em seguida são explorados os conceitos de Inteligência Organizacional e seu Ciclo. Também são examinadas a relação da Informação neste ambiente, sua importância, e os principais tipos de Sistemas de Informação aplicáveis a esta função. Finalmente, como contribuição e um dos principais resultados destacados no estudo, são apresentados subsídios para recomendar um Modelo Conceitual de aplicação de Inteligência Organizacional na função Manutenção.

Palavras-chave: Inteligência organizacional. Sistemas de informação. Manutenção.

\section{Introdução}

Desde a revolução industrial, o homem tem se preocupado em buscar meios de tornar cada vez mais eficientes os processos de transformação, ou seja, utilizar menores quantidades de recursos para mudar o estado ou a condição de algo a produzir. A primeira reação foi a crescente adoção da automação nas atividades de produção, e como consequência, seguida por altos investimentos em equipamentos. A fim de atingir retornos desses investimentos de forma mais rápida, esperava-se que os equipamentos tivessem o maior rendimento possível. Métodos científicos passaram, então, a ser empregados nos processos produtivos. Era apenas o início da incessante busca pela máxima produtividade (LEVITT, 1997; MOUBRAY, 1997; DUFFUAA et al., 1999; PALMER, 1999).

Porém, com a ampliação dos mercados de forma global, as pressões sobre as organizações de manufatura e serviços, para serem mais competitivas e oferecerem produtos e serviços de qualidade, cresceram ao ponto de expandir essa busca por otimização para muito além das fronteiras do "chão de fábrica", envolvendo todos os setores da organização. Como resultado desse processo, a missão das funções de apoio ao processo produtivo, entre elas a
Manutenção, passou a ter necessidade de estar alinhada com a melhoria contínua, que tem ocorrido em todas as áreas da organização. Xenos (1998) lembra que:

$$
\begin{aligned}
& \text { tradicionalmente as atividades de manutenção eram } \\
& \text { consideradas como um mal necessário [...] Mais } \\
& \text { recentemente esta atitude em relação à Manutenção } \\
& \text { começou a mudar e hoje ela já é reconhecida } \\
& \text { como uma função estratégica. [...] até mesmo } \\
& \text { as pequenas interrupções da produção podem } \\
& \text { causar grandes prejuízos. Estes desafios industriais } \\
& \text { colocaram a Manutenção em evidência. A } \\
& \text { Manutenção é indispensável à produção e pode } \\
& \text { ser considerada como a base de toda atividade } \\
& \text { industrial (XENOS, 1998, p.13). }
\end{aligned}
$$

O principal objetivo da Manutenção é preservar a integridade funcional dos recursos envolvidos na produção ou operação de um serviço. Uma vez que a capacidade produtiva e operacional de uma organização está intimamente ligada à disponibilidade e confiabilidade de seus recursos, a Manutenção passa, então, a desempenhar um papel estratégico, como fator capaz de oferecer um diferencial competitivo à organização (LEVITT, 1997; PALMER, 1999). 
Nesse ambiente, um recurso que pode representar o diferencial entre a eficiência e o prejuízo é a informação. A informação para a Manutenção é indispensável, não apenas para sua realização rotineira, de forma eficiente e eficaz, como também para análises e ações futuras, de forma a nortear ou evitar a necessidade de novas intervenções. De acordo com Westerkamp (1997), a Gestão da Manutenção é uma atividade intensamente associada a informações. Nas grandes corporações, a cada curto período, centenas de ocorrências são registradas, ordens de serviço disparadas, materiais requisitados, estudos de engenharia iniciados e planos de manutenção elaborados. Por outro lado, o acesso a esses dados tem necessidade premente por rapidez, confiabilidade e facilidade. Assim, é natural que os Sistemas de Informação tenham alcançado um papel de grande destaque nas atividades de Manutenção. Segundo Tavares e Silva (2001), são comercializados atualmente no mundo mais de trezentos softwares especializados em Manutenção.

Entretanto, de acordo com características descritas por Levitt (1997) e Duffuaa et al. (1999), esses sistemas têm como foco, em geral, a coleta, guarda e disseminação de dados gerados no ambiente operacional: eventos diários de registro de ocorrências, materiais utilizados nas atuações, planejamento de atividades, entre outros; e têm sua aplicação predominantemente voltada às rotinas operacionais da Manutenção e/ou a tarefas de administração da Manutenção como negócio (gestão de recursos materiais e humanos). São comercializados com o apelo de serem excelentes ferramentas para análises no âmbito transacional e tático, fundamentados em análises de eventos passados.

Assim, observando-se esse cenário, nota-se uma lacuna referente a ferramentas e estudos de métodos (relacionados ao tratamento da informação) voltados, especificamente, para a Manutenção, com aplicações direcionadas para um nível de gestão mais estratégico. O que parece um contrassenso, uma vez que esta função, conforme já mencionado, tem assumido um papel cada vez mais importante nas organizações. O uso inteligente da informação surge como uma possível saída para proporcionar à Manutenção um meio de potencializar sua gestão estratégica. Porém, nota-se ainda que grande quantidade de informações de eventos passados, como as obtidas por meio dos tradicionais Sistemas de Informação empregados na Manutenção, não tem se mostrado suficiente para proporcionar a agilidade e a eficiência desejadas no atual mercado competitivo. Gomes e Braga (2002) corroboram essa posição e afirmam que:

possuir grande quantidade de informações ou de dados não é mais suficiente. O diferencial é selecionar e analisar essa profusão de informações, transformando-a em inteligência, de modo que as organizações possam conscientemente se adaptar às exigências do ambiente no qual estão inseridas (GOMES; BRAGA, 2002, p. 21, grifo do autor).

A atividade sistematizada que aborda a ideia descrita por Gomes e Braga (2002) é conhecida como Inteligência Organizacional ou, ainda, Inteligência Competitiva.

Diante da percepção do cenário exposto, principal fator motivador da pesquisa, o objetivo principal deste trabalho é propor a aplicação dos conceitos, métodos e ferramentas de Inteligência Organizacional na função Manutenção, com vistas a potencializar sua Gestão e como forma de auxílio ao processo de tomada de decisão nesse ambiente. Para tanto, o estudo aborda as questões conceituais da função Manutenção, a importância da informação nesse ambiente e apresenta um Modelo Conceitual de Gestão de Informação com a integração destas ferramentas, com o propósito de demonstrar a viabilidade teórica da proposta. Um fator motivador complementar para a elaboração desta investigação foi a prévia identificação, junto à bibliografia especializada, da crescente relevância que a Manutenção tem assumido, especialmente no setor industrial, como possível mecanismo de diferencial competitivo, frente à realidade de escassa disponibilidade de estudos e fontes acadêmicas que abordem as relações entre Informação, Inteligência e a função Manutenção.

\section{A função manutenção e a evolução de sua relevância}

Inicialmente o termo manutenção era restrito ao vocabulário militar, no qual teria surgido e, apenas na década de 1950, começaria a ser utilizado pela indústria e incorporado à estrutura organizacional das empresas (MONCHY, 1989). Com o passar do tempo, novas definições foram sendo concebidas e aprimoradas, como as que serão apresentadas a seguir.

A Norma TB 116 da Associação Brasileira de Normas Técnicas (ABNT), em 1975, descreveu Manutenção como sendo todas as ações necessárias para que um item seja conservado ou restaurado de modo a poder permanecer de acordo com uma condição especificada (ASSOCIAÇÃO BRASILEIRA DE NORMAS..., 1975). Na revisão de 1994, da mesma Norma, NBR 5462 (Confiabilidade e Mantenabilidade), a definição de Manutenção passou a ser a combinação de todas as ações técnicas e administrativas, incluindo as de supervisão, destinadas a manter ou recolocar um item em um estado no qual possa desempenhar uma função requerida (ASSOCIAÇÃO BRASILEIRA DE NORMAS..., 1994). Pode-se notar uma evolução no conceito, incorporando o sentido de preservação de função e não apenas conservação pura do ativo.

Um outro ponto que merece ser ressaltado nas definições mais recentes é a preocupação com os custos. Nesse sentido, Levitt (1997, p. 1) afirma que “[...] a função da manutenção 
é preservar um ativo ou preservar a habilidade de um ativo para, de modo seguro e econômico, produzir algo". Apesar de, no senso comum, a Manutenção tradicionalmente estar associada a reparos e consertos, Levitt (1997, p. 1) lembra que a definição da palavra manutenção está na realidade relacionada à "ação de manter num preservado estado" e, assim, não há relações exclusivas com reparos. A partir dessa ideia presume-se que, ao se mencionar Manutenção, faça-se referência a ações que evitem a ocorrência de falhas, por meio da preservação da função do ativo, e não apenas efetuando consertos ou reparos.

Diante das definições pesquisadas percebe-se que as mais recentes já possuem essa nova visão da Manutenção, que se refere à preservação de um estado funcional e não apenas à preservação do equipamento, afastando-se, cada vez mais, do conceito clássico de conservação pura $e$ simples do ativo.

Atualmente, com a busca constante por mais qualidade e produtividade, a Manutenção está cada vez mais relacionada também com a segurança e questões ambientais. Moubray (1997) lembra que dois dos piores acidentes industriais da história - Usina Nuclear de Chernobyl, em 1986, vazamento de 50 toneladas de material radioativo, 125 mil mortos entre 1988 e 1994, vítimas da radiação; e Plataforma de petróleo de Piper Alpha, em 1988, 167 mortos e US\$ 2,8 bilhões de prejuízo - tiveram atividades de manutenção envolvidas como fatores iniciais dessas catástrofes. Eventos de grandes proporções, como o atentado ocorrido em 11 de setembro de 2001 em Nova York, ou o black-out que atingiu parte dos Estados Unidos e o Canadá em agosto de 2003, ilustram e reforçam a importância dos Planos de Recuperação de Desastres e de Continuidade de Negócios - conhecidos, também, por suas iniciais na língua inglesa, Disaster Recovery (DR) e Business Continuity Plan (BCP) -, ambos, geralmente, sob a responsabilidade da função Manutenção.

Reforça-se assim que a Manutenção, em seu processo evolutivo, tem assumido cada vez mais um papel de destaque, não apenas no setor industrial, mas também, nos mais variados tipos de serviços, como transportes, hospitais, centros comerciais, comunicação e bancos.

Pode-se afirmar que a importância estratégica da Manutenção tem crescido, basicamente, em função da expansão de seu papel inicial de manter a integridade física dos ativos para o foco de preservar a função dos ativos, além de melhorar sua disponibilidade e segurança, assim como ajudar a garantir a qualidade dos produtos produzidos e, mais recentemente, sem agredir o meio ambiente (MOUBRAY, 1997; PALMER, 1999; TAKATA et al., 2004; MULLER et al., 2008).

No passado, em especial no período anterior à Segunda Guerra Mundial, a função Manutenção possuía seu foco em reparar ou restabelecer fisicamente equipamentos, apenas depois da quebra. Com o desenvolvimento da
Engenharia da Confiabilidade, a partir da década de 1950, os conceitos de manutenção preventiva começaram a ser aplicados, buscando evitar a quebra. Na década de 1970 surgiu a teoria da Manutenção Baseada na Condição, na qual a manutenção preventiva era realizada baseada em sintomas de falhas reconhecidas e analisadas por meio de técnicas de monitoração ou diagnósticos, o que aumentou a precisão do momento adequado da intervenção.

A partir de então, surgiram novos desdobramentos dessas estratégias - por exemplo, a Manutenção Centrada em Confiabilidade, a Manutenção Baseada em Riscos, a Baseada em Inspeções etc. Assim, por volta de 1990, cresceu exponencialmente a "importância" da melhor seleção possível da apropriada estratégia de manutenção a ser aplicada, de acordo com o cenário no qual a corporação e consequentemente seus ativos estavam inseridos, com um propósito comum: tornar a função Manutenção cada vez mais transparente (imperceptível para a Produção) e eficiente. Neste contexto, o uso de Sistemas de Informação nesse ambiente vai ao encontro deste desafio (MOUBRAY, 1997; KARDEC, NASCIF, 2001; TAKATA et al., 2004; MA, 2007).

\section{Sistemas de informação na manutenção}

Wireman (1994) e Levitt (1997) enfatizam que, para proporcionar um melhor controle, há a necessidade de se identificar todas as atividades envolvidas na Manutenção em "ordens de serviço". Ordens de serviço são registros sobre as tarefas de manutenção, planejadas ou realizadas, que contêm geralmente dados sobre os recursos materiais e humanos, datas, horários, regras e procedimentos (STENGL; EMANTINGER, 2001). Esses registros sobre materiais utilizados, tempos demandados na execução de atividades, tipo e qualificação da mão de obra empregada são normalmente a base de toda a informação da Manutenção e são de grande valia inclusive para uma análise histórica das rotinas de manutenção, permitindo que se aprenda com o passado, e que se percebam tendências futuras.

Xenos (1998) também observa como os dados registrados formam um importante repositório para análises ou podem servir de fonte para futuro aprendizado dos recursos humanos da manutenção:

as informações que formam o conhecimento e a experiência das equipes de manutenção sobre os equipamentos são oriundas, principalmente, dos registros de falha gerados através de sistemas de tratamento de falhas dos equipamentos. Os dados sobre falhas e sobre as melhorias introduzidas nos equipamentos existentes se tornam um valioso "aprendizado" para as equipes de manutenção (XENOS, 1998, p.167).

Para o registro histórico e posterior análise das informações da rotina de manutenção, diversos sistemas têm sido 
disponibilizados no mercado ao longo do tempo, incorporando cada vez mais funcionalidades e tecnologia.

Westerkamp (1997) afirma que um dos desafios da Manutenção envolve necessariamente lidar com essa grande quantidade de informações e, por esse motivo, os sistemas de informação são ferramentas particularmente bem aplicáveis no controle das atividades de manutenção e na sua própria gestão.

Há no mercado atualmente uma enorme variedade de sistemas de informação computadorizados e, de certa forma, pelo fato de a manutenção ser uma área bastante ampla, praticamente não existem restrições para aplicação desses sistemas nessa área. Entretanto, o que se nota, na prática, é que determinados sistemas de informação são mais frequentemente citados na literatura sobre manutenção (DUFFUAA et al., 1999; PALMER, 1999; WIREMAN, 1994; LEVITT, 1997; TURBAN et al., 2004; WESTERKAMP, 1997; STENGL; EMANTINGER, 2001). Desde os mais simples aos mais sofisticados, dos específicos aos mais abrangentes, atualmente os sistemas mais aplicados no ambiente de manutenção são:

- Sistemas Computadorizados para Gestão da Manutenção (CMMS - Computerized Maintenance Management Systems);

- Sistemas Especialistas;

- Sistemas de Gerenciamento Eletrônico de Documentação (GED); e

- Sistemas de Gestão de Material.

\section{A inteligência organizacional}

A inteligência, remetida ao contexto da informação, está geralmente relacionada a um ato, a uma ação de escolha da melhor alternativa dentre todas as analisadas, baseada nas informações obtidas. Fernandes et al. (1999, p. 35) entendem que a "Inteligência é a compreensão adquirida que permite chegar à melhor decisão". Shapiro afirma que:

inteligência é a resultante de um processo de aquisição, armazenamento na memória, recuperação, combinação, comparação e uso em novos contextos de informações e habilidades (SHAPIRO, 1987, p. 432, tradução livre do autor)

Segundo Miller (2002, p. 35), "os dados, quando organizados, tornam-se informação; as informações, quando analisadas, transformam-se em inteligência". A inteligência é, desta forma, a capacidade de processamento de informações. É receber informação e saber transformá-la em algo útil em situações diversas. Nesse sentido, para que as organizações operem eficazmente é indispensável um sistema de coleta e análise de informações, assim como, de forma análoga, para que um avião trafegue de forma segura e confiável é indispensável o apoio de um radar (MILLER, 2002). Mas, se a informação é tão importante para a sobrevivência das organizações e está tão perto, por que é tão difícil obtê-la e dela tirar proveito? Talvez a resposta a essa questão esteja no tempo para análise, em contraposição à grande quantidade de informações. Apesar de os gestores reconhecerem que suas organizações são mais eficientes quando tomam decisões bem fundamentadas, a partir de um entendimento adequado do potencial de oportunidades e riscos envolvidos no ramo de atividade, também têm consciência de que, para que isso ocorra, é necessário um processo cuidadoso e minucioso de estudo das questões relevantes. E este processo, consome uma parcela relevante de tempo (MILLER, 2002).

Assim, metodologias e ferramentas para tornar o processo de coleta e de análise de informações sistematizado, ágil e eficiente, são cada vez mais desejadas pelas organizações. Segundo a Sociedade dos Profissionais de Inteligência Competitiva, conhecida pela sigla em inglês $S C I P$, num levantamento feito nos Estados Unidos em 1998, pelo The Futures Group, $82 \%$ das empresas americanas com receita anual maior do que US\$ 10 bilhões, já contavam com algum tipo organizado e estruturado de unidade ou departamento de inteligência em seus organogramas (PRESCOTT; MILLER, 2002).

Porém, a Inteligência, para ser eficaz, deve estar relacionada a uma ação antecipada sobre as possíveis ameaças ou oportunidades descobertas e expostas por meio das informações coletadas. Tomadas de decisão tardias, mesmo realizadas por meio da inteligência, não terão o efeito desejado. Este conceito de ação antecipada é defendido por alguns autores como Lesca et al. (2003) e conhecido como Inteligência Estratégica Antecipativa (IEA), do inglês Environmental Scanning, ou suas variantes Bussiness Intelligence e Competitive Intelligence, e em francês, como Veille Antecipative Stratégique. Esta expressão genérica engloba diversos tipos de inteligência específicos, tais como Inteligência Tecnológica (produtos, serviços, inovação), Inteligência Competitiva (concorrentes e competidores), Inteligência Comercial (clientes), entre outras (LESCA et al., 2003).

Autores como Tarapanoff (2001) e Bergeron e Hiller (2002) utilizam a denominação Inteligência Competitiva ou Inteligência Organizacional para um processo mais amplo e não necessariamente apenas ligado a competidores e concorrência. $\mathrm{Na}$ realidade, o termo Inteligência Organizacional possui diversas definições, ora sendo apresentado como um processo, ora como uma função, um produto ou uma mistura dos três. A terminologia também é variada e usada indiscriminadamente, para se referir às mesmas áreas e práticas. Os termos Inteligência Competitiva, Organizacional, do Competidor, Empresarial, Estratégica, Social, em Negócios (ou mais conhecido no inglês como Business Intelligence - que segundo Serra (2002) é um termo freqüentemente mais associado às ferramentas de tecnologia), ou ainda, Monitoração Ambiental, Vigília 
Estratégica e Radar Informacional são apresentados como os termos mais comumente encontrados que se referem à Inteligência Organizacional ou dela derivados (OLIVEIRA; CAVALCANTI, 2002; BERGERON; HILLER, 2002).

Silva (2003) busca esclarecer as diferenças entre as terminologias Inteligência Competitiva e Inteligência Organizacional. A autora indica que a Inteligência Competitiva é um processo que possui o foco voltado ao "Ambiente Externo". Em sua interpretação, a Inteligência Competitiva é, na verdade, parte do processo mais amplo de Inteligência Organizacional que possui o foco tanto no "Ambiente Interno" como no "Externo". Para os propósitos deste estudo, a denominação adotada será, de forma genérica, Inteligência Organizacional.

De acordo com a definição elaborada pelo Grupo de Estudos em Sistemas de Informação e Apoio à Decisão (GESID, 1999 apud CANONGIA et al., 2001), Inteligência Organizacional refere-se ao "conjunto de atividades de monitoramento e de análise de dados do ambiente com o objetivo de fornecimento de informações úteis ao processo decisório e de planejamento estratégico empresarial". Em resumo, pode-se entender que a Inteligência Organizacional fornece a metodologia e as ferramentas para monitorar todo esse ambiente (interno e/ou externo) e para obter as informações advindas dele, visando permitir que sejam aproveitadas as oportunidades e identificadas e contornadas as possíveis ameaças.

Das ferramentas computadorizadas mencionadas por especialistas em Inteligência Organizacional (TARAPANOFF, 2001a), classificadas por Turban et al. (2004) em Sistemas de Suporte Inteligente, ou por Falsarella et al. (2003) de "Sistemas de Inteligência de Negócios", destacam-se, para os propósitos deste estudo, o Data Warehouse (Armazém de Dados) e o Data Mining (Mineração de Dados).

Data Warehouse é, na prática, um repositório de dados com finalidade analítica, com características diferentes e de concepção geralmente isolada dos sistemas transacionais, apesar de normalmente serem esses últimos sua principal fonte de dados (CABENA et al.,1997). Nóbrega (2001) discorre sobre o objetivo do Data Warehouse e também ressalta a importância dessa ferramenta para apoiar o processo de tomada de decisão:

o objetivo geral de um Data Warehouse é fornecer informações confiáveis, ágeis, flexíveis, integradas, para apoiar o processo decisório. [...] Somente quando os indivíduos decidem utilizar o Data Warehouse como insumo essencial do processo decisório, pode-se afirmar que o objetivo do DW começa a ser atingido (NÓBREGA, 2001, p. 287).

Desta forma, apesar de inicialmente parecer algo indesejável, um Data Warehouse contém, na verdade, dados redundantes em relação aos existentes nos outros sistemas de informação de uma organização, sejam eles departamentais ou corporativos, porém com a diferença de possuir a finalidade de atender a necessidades informacionais ou analíticas. É exatamente essa redundância que permite, com auxílio da tecnologia atual, o acesso a dados importantes para a tomada de decisão, num local único, com histórico mais completo, de forma mais fácil e rápida, sem provocar interferência na operação dos sistemas transacionais, uma vez que os dados ficam isolados.

Já a ferramenta Data Mining é definida como um "[...] processo de extração de informação útil, válida e desconhecida de grandes bancos de dados, com o intuito de utilizá-la para cruciais tomadas de decisão em negócios" (CABENA et al., 1997). Os grandes bancos de dados, aqui mencionados, se referem tanto àqueles compostos por bancos de dados tradicionais como por Data Warehouses.

Para Benoit (2002), Data Mining é um processo formado por vários estágios, que possui o intuito de extrair conhecimento desconhecido de grandes bancos de dados, com resultados que podem ser aplicados nos processos decisórios.

É importante esclarecer que vários autores fazem grande distinção entre o "processo" Data Mining e a "etapa" data mining (que faz parte do processo), o que tem causado uma certa confusão nos conceitos (Benoit, 2002). Nessas duas definições propostas por Cabena et al. (1997) e por Benoit (2002), o conceito exposto abrange não apenas a etapa de garimpagem ou mineração de dados (extração e filtragem) propriamente dita, e sim todo um processo de obtenção de informação, posteriormente transformada em conhecimento, com vistas à aplicação no auxílio aos processos decisórios.

Apesar do processo de "descoberta de conhecimento em base de dados" ser algo que remonta a meados de 1960, apenas por volta de 1995, muito em função da evolução das técnicas e dos recursos computacionais, começou a se consolidar como uma solução viável. Nessa mesma época surge entre os pesquisadores uma nova e diferente nomenclatura para denominar o processo de Data Mining, o KDD (Knowledge Discovery in Databases) (TURBAN et al., 2004; CABENA et al., 1997; BENOIT, 2002).

Desta forma, pode-se entender que, na prática, o processo de Data Mining e o KDD são sinônimos, porém a denominação KDD é mais recente e a expressão Data Mining passou a ser referenciada apenas como uma das várias etapas de um processo de KDD. Mais adiante se pode verificar como tais ferramentas podem ser úteis no ambiente de manutenção.

\section{0 ciclo da inteligência organizacional}

Davenport (2000) menciona, de forma genérica, as vantagens de se visualizar um trabalho ou tarefa como um processo. Em sua análise, o gerenciamento da informação tem características que se adaptam perfeitamente a essa 
abordagem processual. Assim, um processo de gerenciamento da informação, uma vez minuciosamente descrito, dividido em subprocessos ou passos, ordenado, e com todas as fases identificadas, facilita sua mensurabilidade e seu aperfeiçoamento.

De forma análoga, a Inteligência também pode ser vista como um processo. E um processo de Inteligência, pode ser estruturado em etapas, constituindo um fluxo denominado por alguns autores de Ciclo da Inteligência (FERNANDES et al., 1999; CANONGIA et al., 2001; GOMES; BRAGA, 2002; MILLER, 2002). A forma de divisão, a quantidade de etapas, assim como a nomenclatura adotada para cada etapa, varia conforme o autor. Apesar da diversidade de formas apresentadas na bibliografia analisada, há quatro etapas do Ciclo de Inteligência que se destacam e são consideradas, de maneira mais frequente, nos modelos vistos: Planejamento, Coleta, Análise e Disseminação.

Na análise de Santos (2000), a partir da Norma XP 50-053, a etapa de Planejamento ("Definição/redefinição dos eixos de vigília e das finalidades do cliente") é o momento no qual é determinado o Campo de Interesse que a organização deseja observar. Assim, independente da natureza do assunto, que pode ser, por exemplo, técnica, econômica, social, política, jurídica, formula-se a demanda de informação, explicitando-se as necessidades e finalidades do cliente. Ainda nessa etapa, os assuntos são priorizados segundo sua criticidade para os negócios da organização, ou seja, o quanto tais dados ou informações podem comprometer a continuidade de suas operações, ou até sua própria existência. Por outro lado, identificam-se também dados ou informações que possam representar oportunidade de negócios e/ou ganhos expressivos e vantagem competitiva.

A etapa seguinte é a Coleta de dados e informações. Nela são determinados os processos mais adequados e os modelos de análise que serão utilizados para obter as informações (MILLER, 2002). A coleta tem início logo após a identificação das fontes. Elas designam aqueles que detêm os dados ou informações e como podem ser classificadas: primárias ou secundárias. As primárias são as fontes que contêm fatos não alterados, obtidos diretamente da sua origem. As secundárias, aquelas que podem apresentar alguma modificação em relação à sua origem (FERNANDES et al., 1999).

O passo seguinte é a etapa de Análise, baseada na identificação de padrões e tendências significativas, por meio da busca de relações, até então não detectadas entre os dados. Gomes e Braga (2002) afirmam que esta etapa, por sua importância no processo, deveria ser chamada de "geradora de inteligência". É necessário que o analista saiba expandir o raciocínio analítico para além da pesquisa imediata, utilizar-se de pensamento lógico organizado, segundo padrões que não se apresentam necessariamente em sequência, porém sem perder o foco no objetivo definido (FERNANDES et al., 1999; MILLER, 2002).
A Disseminação, última etapa do ciclo, aborda a divulgação e a entrega da informação tratada já num formato adequado ao usuário. Esse formato, segundo Miller (2002), pode se apresentar das mais diversas formas, desde relatórios impressos, sumários, eletronicamente num ambiente de rede ou até mesmo por meio de contato pessoal em reuniões formais e informais.

\section{Proposta de modelo de inteligência organizacional aplicado à manutenção}

Diante de todo o panorama explicitado, surgem alguns questionamentos: Como obter informações que poderiam antever ameaças à gestão da Manutenção? Como extrair conhecimento não explícito de uma massa de dados armazenados nos tradicionais Sistemas de Informação utilizados na Manutenção? Seria possível aplicar modelos de Inteligência à Manutenção, como forma de potencializar sua gestão?

Para tanto, retomaremos o conceito de Inteligência Organizacional como um processo sistemático de planejamento, coleta, análise e disseminação da informação pública (provenientes de fontes seguras e balizadas, por exemplo: Diário Oficial, registro de patentes, publicações científicas, entre outras), que possui importância estratégica. É importante destacar que entre seus principais objetivos está a eliminação ou redução de surpresas e incertezas, a otimização do tempo de reação frente às ameaças e a busca por novas oportunidades de negócio. Por sua vez, vimos que a Manutenção tem como um de seus principais objetivos a preservação de um estado funcional aliado a implementações de melhorias. Para realizar esta tarefa de forma eficaz, entendemos que é importante para a Manutenção estar atenta às possíveis ameaças e incertezas à continuidade operacional.

Uma vez que os objetivos da Manutenção e da Inteligência Organizacional estão entrelaçados, com o foco na sustentação e preservação de uma posição estratégica, visando evitar surpresas e incertezas, parece interessante buscar a relação entre as duas disciplinas. É exatamente neste contexto mais geral que se norteia a ideia de apresentar a proposta de um modelo conceitual sugerindo uma análise mais aprofundada dessa correlação.

Como ilustração ao entendimento do modelo a ser apresentado, consideremos um exemplo hipotético de um departamento de manutenção de uma organização de grande porte. Dentro das atividades rotineiras desse departamento se realizam todas as atividades comuns a qualquer setor de manutenção: tarefas de manutenção preventiva programadas, atividades de restabelecimento (corretivas), estudos de melhorias e reformas e desenvolvimento de novos métodos e processos para tornar o setor mais eficiente. Todas as atividades são registradas em sistemas de manutenção 
informatizados, gerando dezenas de milhares de registros mensais.

Tal organização hipotética segue o padrão comum da maioria dos departamentos de manutenção:

- a análise periódica dos registros históricos de atividades em busca de identificação de tendências de ocorrências;

- utiliza como fonte de informações setores predominantemente internos à organização; e

- não possui uma sistemática de coleta e análise de informações externas para tomada de decisão.

Nessa organização, tal padrão resulta em atividades predominantemente de teor reativo e geralmente emergenciais. Ela apresenta vulnerabilidade a surpresas e podem ocorrer frequentes perdas de oportunidades de negócio.

O modelo, apresentado na Figura 1, no qual se sugere o uso da Inteligência Organizacional em um ambiente de Manutenção, é basicamente a representação gráfica do agrupamento e integração, de forma estruturada e correlacionada, de diversos conceitos aqui abordados, que busca justamente promover melhorias ao processo de tomada de decisão em organizações, como no exemplo hipotético anterior. Tal modelo dispõe dos seguintes componentes:

1) Ciclo da Inteligência Organizacional: decomposição do processo de inteligência em várias etapas.

2) Variáveis informacionais: informações provenientes do ambiente interno ou externo que possam representar ameaças à continuidade operacional ou oportunidades de novos negócios.

3) Sistemas de Informação: composto pelo conjunto de Sistemas de Informação mais tradicionais da Manutenção (CMMS, Gestão de Materiais, GED e Sistemas Especialistas) somados aos sistemas de informação e ferramentas de inteligência (Data Warehouse (DW) e Knowledge Discovery in Database (KDD).

O modelo se baseia na obtenção de Inteligência (ações), por meio de informações processadas para subsidiar o processo de tomada de decisão, utilizando-se como fontes os Sistemas de Informação e as Variáveis Informacionais aplicadas ao Ciclo da Inteligência Organizacional. Assim, no exemplo da organização hipotética apresentado, suas rotinas de Manutenção e sua própria gestão seriam beneficiadas com informações relevantes ao processo, obtidas de forma antecipada e sistemática.

O cerne do modelo proposto é o próprio Ciclo da Inteligência Organizacional, com suas etapas de Planejamento, Coleta, Análise e Disseminação de informações para auxiliar o processo de tomada de decisão. Optou-se por adotar no modelo as quatro etapas mais citadas na literatura científica, porém a abrangência de seus conteúdos é mais ampla do que os termos utilizados possam induzir. Etapas importantes como a validação da informação coletada, a checagem de sua real utilização e pertinência, a avaliação de sua temporalidade (avaliação quanto ao tempo de armazenamento e descarte), entre outras, apesar de não serem citadas e exploradas neste modelo, foram consideradas como embutidas nessas 4 etapas clássicas.

É pressuposto que, para uma efetiva implementação do modelo, a Manutenção deva possuir em seu quadro de colaboradores uma equipe de analistas de inteligência ou de profissionais contratados com as competências requeridas, mencionadas na Norma AFNOR XP X 50-053 (apud SANTOS, 2000), além de possuírem profundos conhecimentos sobre o negócio Manutenção. Uma outra proposta, sugerida por Ansoff e McDonnell (1993), pode ser a criação de Comitês Multidisciplinares que atravessam fronteiras organizacionais normais e se comunicam com empregados considerados elementos-chave (tomadores de decisão) diante de surpresas estratégicas. Os membros desse comitê receberiam, sob demanda, informações de analistas de inteligência e seriam treinados para darem respostas imediatas a problemas novos, combinando criatividade, técnicas analíticas e trabalho de equipe.

Nesse cenário, durante a etapa de Planejamento, os analistas de inteligência da Manutenção seriam os responsáveis por identificar e definir que tipos de informação devem ser considerados realmente relevantes e necessários para auxiliar nos processos de tomada de decisão na Manutenção. Além disso, nessa etapa também são analisadas e escolhidas as possíveis fontes dessas informações (sistemas de informação transacionais, analíticos, ambiente externo, entre outras). Conforme recomendado por vários autores (GOMES; BRAGA, 2002; MILLER, 2002; PRESCOTT; MILLER, 2002), para esta etapa podem ser utilizadas, por exemplo, técnicas de entrevistas com integrantes da alta administração da Manutenção.

Na etapa de Coleta identifica-se onde estão, como capturar, selecionar, classificar e organizar as informações requeridas para a inteligência na Manutenção. Para tanto, o analista de inteligência da Manutenção deve conhecer profundamente as possíveis fontes de informação desse ambiente. Para um melhor entendimento dessa importante etapa, basicamente o modelo pode ser dividido em função da origem das informações. Na parte superior do modelo as informações coletadas são aquelas provenientes fundamentalmente do ambiente externo (informações provenientes tanto do ambiente externo à Organização como externo à Manutenção), fruto das, aqui denominadas, Variáveis Informacionais. Já na parte posterior do modelo estão as informações coletadas internamente por meio dos Sistemas de Informações computadorizados, tanto dos tradicionalmente utilizados na Manutenção, como daqueles relacionados à Inteligência Organizacional $(D W$ e $K D D)$.

Para ilustrar a questão das Variáveis Informacionais, voltamos a utilizar a organização hipotética como exemplo: 

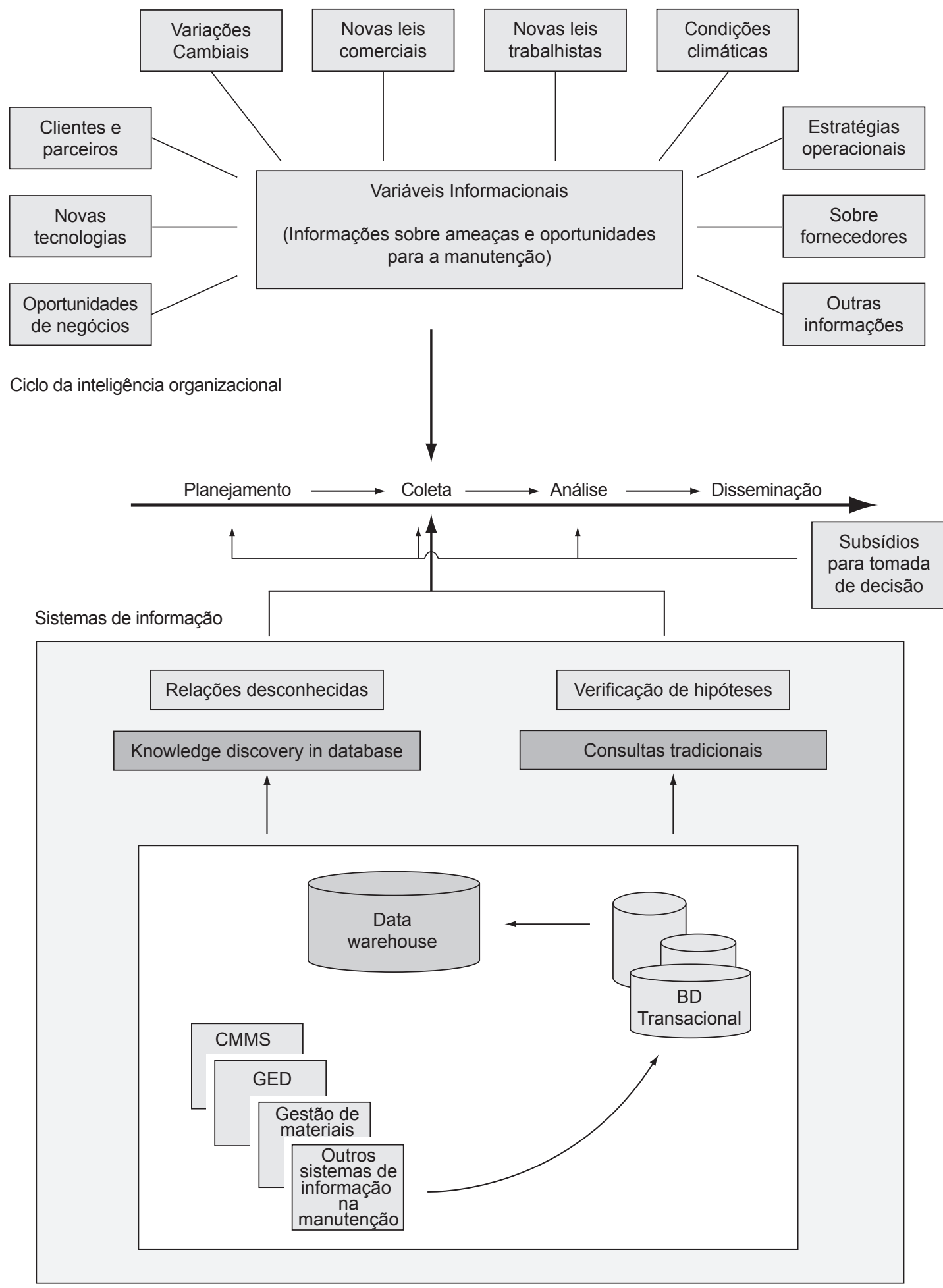

Figura 1. Modelo Conceitual: Inteligência Organizacional aplicada à Manutenção.

Fonte: Gerada pelos autores.

consideremos que os analistas de inteligência de nossa organização fictícia obtiveram num processo de coleta de informações externas, fortes indícios sobre a eminência de uma greve de empregados em uma empresa fornecedora de exclusivos componentes sobressalentes para a manutenção de determinado equipamento, fundamental para a continuidade dos negócios da empresa. Pode ser uma informação obtida por meio da imprensa ou de contatos com empregados da empresa fornecedora. Trata-se de uma séria ameaça em potencial e assim, uma vez conhecendo essa informação, 
o departamento de manutenção da organização citada, poderia, antecipadamente, tomar ações preventivas, de forma a contornar possíveis problemas de falta desses sobressalentes para sua atuação.

Da mesma forma, as Variáveis Informacionais podem proporcionar informações relevantes a novas oportunidades de atuação da Manutenção, como novos métodos, novas tecnologias, novos negócios (por exemplo a prestação de serviços a outras empresas, consultorias, treinamentos, intercâmbios), possibilitando a redução de custos e aumentando sua eficiência. Ou seja, potencializar a Manutenção também em seu papel de negócio.

Por sua vez, observando-se o modelo em sua parte inferior, ainda na etapa de Coleta, são vistos como fonte de informação os Sistemas de Informação. No caso dos Sistemas de Informação tradicionais na Manutenção é notória sua importância para recuperação de informações relevantes ao processo decisório. Neles estão contidos dados sobre as questões operacionais e rotineiras, registrados pelo pessoal da Manutenção que, após o devido tratamento, se tornarão rica fonte de informação e conhecimento, gerando indicadores de performance de diversos tipos, permitindo verificação e comprovação de hipóteses.

Em nossa organização hipotética, são exemplos desses dados: registros de manutenção sobre mão de obra aplicada, tempos demandados, materiais consumidos, documentação técnica utilizada, entre dezenas de outros. Nesse caso, a Coleta se daria por meio de consultas tradicionais diretamente ao banco de dados desses Sistemas de Informação informatizados.

O modelo também apresenta como proposta, que a etapa de Coleta se abasteça de informações provenientes de Sistemas de Informação e ferramentas de inteligência aplicadas à Manutenção. Por meio desses sistemas, como o Knowledge Discovery in Database, os analistas de inteligência da Manutenção podem obter relações desconhecidas contidas nos bancos de dados dos Sistemas de Informação tradicionais da Manutenção e/ou também de um Data Warehouse, ferramenta de inteligência concebida para agrupar tais informações. É importante ressaltar que o DW no modelo também pode ser utilizado como fonte para consultas tradicionais, sem uso do KDD e que este representa apenas uma simplificação do processo de transformação de um banco de dados tradicional para um DW.

Para ilustrar a proposta de utilização de DW e ferramentas de inteligência, recorreremos novamente ao departamento de manutenção de nossa organização hipotética: um exemplo simples seria a descoberta nessa massa de dados, sem uma hipótese prévia, e por meio da etapa de Coleta dos analistas de inteligência da organização, de que há uma forte relação entre o consumo exagerado de um determinado tipo de material sobressalente e as datas de revisão de um documento técnico de manutenção.
Ou seja, percebeu-se uma correlação desconhecida entre os dados registrados: todas as vezes em que determinado procedimento de manutenção documentado sofreu uma revisão notou-se, paralelamente, o incremento de consumo de certo componente sobressalente. Se essa relação identificada realmente possui consistência e relevância para os processos de Manutenção é uma verificação que se dará na etapa seguinte do Ciclo de Inteligência: a Análise.

É na etapa de Análise que são aplicadas técnicas e métodos analíticos sobre as informações coletadas, de forma a avaliá-las e transformá-las em um recurso útil. Apesar do produto final do ciclo de Inteligência Organizacional - informação útil para auxiliar o processo de tomada de decisão - se formar completamente apenas após a próxima etapa (disseminação), é nesse instante que são realizados estudos, observações, comparações e são obtidas as possíveis conclusões e tendências sobre as informações coletadas, pelos analistas de inteligência. Sendo assim, uma análise mal realizada poderá produzir informações distorcidas e comprometer seriamente a qualidade das decisões decorrentes.

Na sequência do Ciclo da Inteligência, está ainda representada no modelo, a etapa de Disseminação da informação. É nesse momento que os analistas de inteligência verificam qual a melhor maneira de divulgar as informações obtidas ao grupo tomador de decisão da Manutenção. Podem ser elaborados relatórios, sumários, gráficos, tabelas, memorandos e semelhantes, impressos ou eletrônicos (utilizando recursos como intranet, sites, redes) ou ainda a divulgação ocorrer de forma verbal, por meio de apresentações em reuniões e palestras internas.

Assim, uma vez efetuado o planejamento do que é necessário se obter de informações, concebida a coleta dessas informações, concluídas todas as análises, obtendo-se novos conhecimentos sobre ameaças, oportunidades, relações desconhecidas entre informações e verificação de hipóteses no ambiente de Manutenção e realizada a disseminação desses novos conhecimentos, o corpo gestor da Manutenção obterá importantes subsídios para auxiliá-lo em seus processos decisórios, completando, dessa forma, o Ciclo da Inteligência Organizacional aplicado a esse ambiente. Ressalta-se por fim, que todas as etapas do Ciclo são interativas e iterativas, ou seja, além de ser um processo cíclico e dinâmico, no qual as necessidades de informações estão sempre em mutação em função do momento e contexto histórico da Manutenção, uma etapa influencia e recebe influência dos resultados das demais e podem ser repetidas diversas vezes até a obtenção do produto desejado.

\section{Conclusões}

As publicações mais recentes denotam que a Manutenção obtém, dia após dia, um papel de destaque e importância no mundo corporativo (TAKATA et al., 2004; MA, 2007; 
SODERHOLM, 2007; MULLER et al., 2008). Antes vista, e cercada de preconceitos, como uma área geradora de despesas, voltada apenas a "consertar" coisas, passa lentamente a obter reconhecimento notório ao se posicionar como um dos poucos setores, especialmente no ramo industrial, em que ainda há certo espaço para saltos de eficiência. Isso reitera nossa proposição inicial de que a Manutenção tem potencial importância como disciplina a ser levada em consideração na elaboração da estratégia competitiva das organizações. Apesar de ainda escasso, é cada vez maior o número de eventos, publicações e estudos voltados para esse setor. A aplicação de ferramentas e métodos modernos de gestão é apenas uma consequência natural desse processo. Este trabalho busca contribuir para esse processo de reconhecimento ao propor, por meio da fundamentação teórica da Ciência da Informação, o uso da Inteligência Organizacional nesse ambiente.

Entende-se que a inovação apresentada no estudo é, além de propor à Manutenção a utilização de métodos, ferramentas e procedimentos de Inteligência Organizacional, ressaltar a importância de a Manutenção lançar olhares, em busca de informações, também no ambiente externo à organização, e à própria Manutenção, e não apenas se concentrar nas informações acerca de suas atividades rotineiras, como a literatura estudada ressalta. Tal qual um radar, sistematicamente rastreando o ambiente externo e interno à organização em busca de "sinais", que possam representar possíveis ameaças à continuidade operacional dos ativos confiados à Manutenção e/ou à sua própria estratégia de atuação, é uma forma que mostra ser teoricamente possível de potencializar a gestão dessa importante função.

Destaca-se, de forma geral, que as possíveis vantagens e benefícios para a Manutenção proporcionados pela aplicação do modelo conceitual proposto são:

- Propiciar a prospecção e o mapeamento, tanto do ambiente interno como do externo, de informações sobre possíveis eventos, fatos e acontecimentos, que poderiam provocar impactos nas funções operacionais da Manutenção, afetando indiretamente a disponibilidade de equipamentos e sistemas, de forma que, de posse dessas informações e após uma completa análise e disseminação, a Gestão da Manutenção poderá ter condições de tomar ações, de forma antecipada, em relação a essas ameaças.

- Propiciar a prospecção e o mapeamento, tanto do ambiente interno como do externo, de possíveis oportunidades de novos negócios.

- Permitir a prospecção de informações e a descoberta de conhecimentos ocultos nos tradicionais repositórios de dados da Manutenção, suportados pelo uso de ferramentas de Inteligência, como o DW e o KDD, como forma de apoiar a identificação de novas relações, inicialmente invisíveis, entre esses dados e potencializar os processos de tomada de decisão.
No âmbito da gestão administrativa da Manutenção, destacam-se algumas das possíveis vantagens na aplicação da Inteligência Organizacional:

- Melhor previsibilidade na análise de riscos e impactos: obtenção de dados sobre mapeamento de riscos para a continuidade operacional. Redução do tempo de reação frente a ameaças, tomadas de decisão mais ágeis e fundamentadas; elaboração de planos de contingência e de recuperação de desastres com antecedência, frente ao grau de risco detectado.

- Mapeamento de aspectos legais: alterações em leis, com possíveis impactos na gestão de mão de obra, materiais, questões ambientais (poluição, descarte de inertes). São exemplos, impedimentos legais para uso e/ou manipulação de certos tipos de materiais, como óleo ascarel e placas de amianto, alterações em leis quanto à obrigatoriedade de pagamentos de adicionais de periculosidade e insalubridade.

- Mapeamento de aspectos econômicos: como exemplo cita-se a descoberta de eminente e forte alteração na política cambial, afetando a reposição de insumos importados para a manutenção.

- Alinhamento com o planejamento estratégico da área de operações: identificação de qual o planejamento estratégico para a área de operações da empresa (principal cliente da manutenção), quais suas metas, quais suas necessidades e requisitos.

- Mapeamento de novas tecnologias: obtenção de informações sobre inovações tecnológicas que podem transformar a forma de atuação da Manutenção.

- Mapeamento de alterações na forma de utilização ou criticidade do ativo (exemplo: microcomputadores com uso administrativo que passaram a ter uso operacional para controle de processos de missão crítica).

- Detecção antecipada de mudanças tecnológicas profundas em ativos: como exemplo pode-se citar a alteração da tecnologia das centrais telefônicas, que eram eletromecânicas e atualmente são totalmente digitais: há ainda peças de reposição? Por quanto tempo? Há mão de obra treinada no mercado (caso seja terceirizada)?

O presente artigo buscou uma abordagem panorâmica e teórica sobre a investigação do possível uso da Inteligência Organizacional no ambiente de Manutenção. Por ser um estudo teórico, os autores reconhecem a necessidade e fornecem estímulo a novos estudos complementares e ensaios práticos que possam validar e consolidar o modelo aqui proposto, assim como suscitar outras discussões sobre o tema. 


\title{
Application of an organizational intelligence conceptual model in plant maintenance
}

\begin{abstract}
This study presents an investigation through a bibliographical research on Information Systems, the tools, and the methods of Organizational Intelligence focusing on the application in Maintenance environments as instruments to empower the management of productive processes. In view of this, the Maintenance concepts and its increasing relevance are primarily discussed. Afterwards, the concepts of Organizational Intelligence and its Cycle are explored. Moreover, information and its importance in Maintenance environments, and the main adequate Information Systems are also investigated. As a result, the application of an Organizational Intelligence Conceptual Model in the plant maintenance is recommended.
\end{abstract}

Key-words: Organizational intelligence. Information systems. Plant maintenance.

\section{Referências bibliográficas}

ANSOFF, I. H.; McDONNELL, E. J. Implantando a administração estratégica. São Paulo: Atlas, 1993. 590 p.

ASSOCIAÇÃO BRASILEIRA DE NORMAS TÉCNICAS - ABNT. TB116: confiabilidade e mantenabilidade. Rio de Janeiro, 1975. Substituída pela NBR 5462.

ASSOCIAÇÃO BRASILEIRA DE NORMAS TÉCNICAS - ABNT. NBR 5462-TB116: confiabilidade e mantenabilidade. Rio de Janeiro, 1994. 37 p.

BENOIT, G. Data mining. Annual Review of Information Science and Technology, v. 36, p. 265-310, 2002.

BERGERON, P.; HILLER, C. A. Competitive intelligence. Annual Review of Information Science and Technology, v. 36, p. 353-390, 2002.

CABENA, P. et al. Discovering Data Mining: from concept to implementation. New Jersey: Prentice Hall PTR, 1997.195 p.

CANONGIA, C. et al. Convergência da inteligência competitiva com construção de visão de futuro: proposta metodológica de sistema de informação estratégica: SIE. Datagramazero: Revista de Ciência da Informação, v. 2, n. 3, 2001. Disponível em: <http:// www.dgz.org.br/jun 04/F_I_aut.htm>. Acesso em: 9 de Março de 2004.

DAVENPORT, T. H. Ecologia da informação: por que só a tecnologia não basta para o sucesso na Era da Informação. São Paulo: Futura, 2000. 316 p.

DUFFUAA, S. O.; RAOUF, A.; CAMPBELL, J. D. Planning and control of maintenance systems: modeling and analysis. New York: John Wiley \& Sons, 1999. 371 p.

FALSARELLA, O. M.; JANNUZZI, C. A. S. C.; BERAQUET, V. S. M. Informação empresarial: dos sistemas transacionais à latência zero. Transinformação, v. 15, Edição especial, p. 141-156, 2003.

FERNANDES, E.; SIMPSON FILHO, P.; CRUZ, P. P. G. Inteligência competitiva: conceitos, ferramentas e aplicações. Brasília: Confederação Nacional da Indústria, 1999. 71 p.

GOMES, E.; BRAGA, F. Inteligência competitiva: como transformar informação em um negócio lucrativo. Rio de Janeiro: Campus, 2002. 120 p.

LESCA, H.; JANISSEK, R.; FREITAS, H. Inteligência estratégica antecipativa: uma ação empresarial. 2003. Disponível em: <www. abraic.org.br/periodicos_teses/ic_a134.pdf >. Acesso em: 17 de Julho de 2004.

LEVITT, J. The Handbook of maintenance management. N.Y: Industrial Press Inc., 1997.

MA, L. Condition monitoring in engineering asset management. In: ASIA-PACIFIC VIBRATION CONFERENCE, 12., 2007, Hokkaido. Proceedings... Hokkaido: Hokkaido University, 2007.

MILLER, J. P. O milênio da inteligência competitiva. Porto Alegre: Bookman, 2002. 293 p.

MONCHY, F. A função manutenção: formação para a gerência da manutenção industrial. São Paulo: Durban, 1989. 367 p.

MOUBRAY, J. Reliability-centered maintenance. Oxford: Butterworth-Heinemann, 1997.

MULLER, A.; CRESPO MARQUEZ, A.; IUNG, B. On the concept of e-maintenance: review and current research. Reliability Engineering and System Safety, v. 93, p. 1165-1187, 2008.

NÓBREGA, R. G. Data warehousing. In: TARAPANOFF, K. (Org.). Inteligência organizacional e competitiva. Brasília: Editora da Universidade de Brasília, 2001. p. 285-302.

OLIVEIRA, L. C. V.; CAVALCANTI, E. P. Um modelo conceitual para avaliação de inteligência empresarial nas organizações. In: AQUINO, M. A. (Org.). O campo da Ciência da Informação: gênese, conexões e especificidades. João Pessoa: Universitária, 2002. p. 245-264.

PALMER, D. Maintenance planning and scheduling handbook. N.Y.: McGraw-Hill, 1999.

PRESCOTT, J. E.; MILLER, S. H. Inteligência competitiva na prática: estudos de casos diretamente do campo de batalha. Rio de Janeiro: Campus, 2002. 371 p.

SANTOS, R. N. M. Métodos e ferramentas para gestão de inteligência e do conhecimento. Perspectivas em Ciência da Informação, v. 5, n. 2, p. 205-215, 2000.

SERRA L. A essência do Business Intelligence. São Paulo: Berkeley, 2002. 288 p.

SHAPIRO, S. C. Enciclopedia of artificial intelligence. New York: Wiley Interscience Publication, 1987. p. 431-440. 
SILVA, H.P. Inteligência competitiva na Internet: um processo otimizado por agentes inteligentes. Ciência da Informação, v. 32, n. 1, p. 115-134, 2003.

STENGL, B.; EMANTINGER, R. SAP R/3 Plant Maintenance: making it work for your business. London: Person Education Limited, 2001. 348 p.

SÖDERHOLM, P.; HOLMGREN, M.; KLEFSJÖ, B. A process view of maintenance and its stakeholders. Journal of Quality in Maintenance Engineering, v. 13, n. 1, p. 19-32, 2007.

TAKATA, S. et al. Maintenance: changing role in life cycle management. CIRP ANNUALS - Journal of Manufacturing Technology, v. 53, n. 2, p. 643-655, 2004.

TARAPANOFF, K. (Org.). Inteligência organizacional e competitiva. Brasília: Editora da Universidade de Brasília, 2001. 343 p.
TARAPANOFF, K. Referencial teórico: introdução. In: TARAPANOFF, K. (Org.). Inteligência organizacional e competitiva. Brasília: Editora da Universidade de Brasília, 2001a. p. 265-278.

TAVARES, L.A.; SILVA FILHO, A.A. Sistemas de gestão integrada de manutenção. In: SEMINÁRIO PLANEJAMENTO E CONTROLE DA MANUTENÇÃO, 2001, Belo Horizonte. Anais... Belo Horizonte: TECEM, 2001. p. 33-42.

TURBAN, E.; McLEAN, E.; WETHERBE, J. Tecnologia da Informação para Gestão: Transformando os Negócios na Economia Digital. Porto Alegre: Bookman, 2004. 660 p.

XENOS, H. G. P. Gerenciando a manutenção produtiva. Belo Horizonte: Editora de Desenvolvimento Gerencial, 1998. 302 p.

WESTERKAMP, T. A. Maintenance manager's standard manual. New Jersey: Prentice Hall, 1997. 848 p.

WIREMAN, T. Computerized maintenance management systems. 2 ed. New York: Industrial Press, 1994. 179 p.

\section{Sobre os autores}

\section{Robson de Paula Alves}

Doutorando em Engenharia de Produção pela Escola Politécnica da Universidade de São Paulo - POLI USP

Mestre em Ciência da Informação, Pontifícia Universidade Católica de Campinas (PUC-Campinas)

Engenheiro Especialista em Manutenção da Cia. do Metropolitano de São Paulo (Metrô)

Av. Francisco de Paula Quintanilha Ribeiro, 134, Jabaquara, CEP 04330-020, São Paulo - SP, Brasil

e-mail: rpalves@metrosp.com.br

\section{Orandi Mina Falsarella}

Diretor do Centro de Ciências Exatas, Ambientais e de Tecnologias - CEATEC

Professor Doutor da Pontifícia Universidade Católica de Campinas - PUC Campinas

Rod. D. Pedro I, Km 136, CEATEC Jd. Santa Candida, CP 317, CEP 13086-900, Campinas - SP, Brasil

e-mail: orandi@puc-campinas.edu.br

Agradecimentos: Agradecimentos à Coordenação de Aperfeiçoamento de Pessoal de Nível Superior (Capes) pelo apoio que possibilitou o desenvolvimento da presente pesquisa.

Recebido em 11/3/2008

Aceito em 8/4/2009 